\title{
Knowledge, Attitude and Practices (KAP) Related to Pre-Conception \& Pre-Natal Diagnostic Techniques (PC \& PNDT) Act Among the Antenatal Women in Bikaner
}

\author{
Mahendra Khatri*, Rekha Acharya, Gaurav Sharma
}

Department of Community Medicine , S.P. Medical College, Bikaner, Rajasthan, India

\begin{abstract}
It was a population based cross sectional study done with the objective of Knowledge, Attitude and Practices (KAP) Related to Pre-Conception \& Pre-Natal Diagnostic Techniques (PC \& PNDT) act among the Antenatal Women in Bikaner district. A population of antenatal women 1000 preference of male child an indicator of gender discrimination was seen, it correlated with female age, literacy, their socioeconomic status, parity. After a detailed the present study showed a clear picture of factors affecting the knowledge and attitude towards the PC \& PNDT Act. The existence of son preference at an alarmingly high rate in our society is the root cause of imbalanced sex ratio. Moreover, the inclination to female feticide is reported by the subjects in spite of them being aware of the consequences of imbalance in sex ratio. Socio-demographic factors like age, literacy, socioeconomic status, parity sex of the previous child and pressure by family or husband affect the knowledge, attitude and practices towards the PC \& PNDT Act and woman's preference for her next child. These days' higher social classes are more vulnerable for misuse of PC \& PNDT Act, doing sex selection, female feticide and preference of male child because they are approaching to more \& more advanced sex determination laboratories and USG centers. And once they came to know about the sex of fetus either illegally abort the female fetus in India or even go abroad for the abortion.
\end{abstract}

Keywords: KAP; PC \& PNDT Act; Gender discrimination; Sex ratio

\section{Introduction}

"Biggest disease today is not leprosy or tuberculosis, but rather the feeling of being unwanted" (Mother Teresa).

"You can tell the condition of a nation by looking at the status of its women" (Pandit Jawaharlal Nehru).

'Women's rights are the edifice on which human rights stand' (Dr APJ Abdul Kalam).

The increase in female feticide has seen the proportionate decrease in female sex ratio which has hit an all time low especially in the 0-6 age group and if this decline is not checked the very delicate equilibrium of nature can be permanently destroyed. Moreover it is not only a problem of numbers. The very status of women and the gains that have been made over the years are at stake. If there are fewer women in society, the violence against women in all its forms would go up and the resultant atmosphere of insecurity would lead to women again being confined within the four walls of the home. The girls would not be allowed to go out to study and women would not be allowed to take up jobs. A time would come when woman would be married off to several men, the manifestations of which are already visible in areas like Dang district of Rajasthan where a woman is living as the wife of eight brothers. Thus the issue of female feticide is one that needs to be addressed urgently. While it is a social problem requiring changing the mindset of people, yet all possible efforts need to be made at every level. Here law can be used as an effective tool to create fear in the minds of those who resort to sex determination or those who carry out such techniques.

India is facing a demographic nightmare in terms of gender imbalance. According to the Census of India, 2011, the sex ratio is low i.e. 940 females per 1000 males. But the more worrying fact is that the child sex ratio (female - male ratio of children below 6 years) is even lower (914 /1000) and has fallen from 927 girls/1000 boys in 2001.
On a national level the sex ratio (per 1000 male ) in the age group 0-6 has declined drastically

1991: 945

2001: 927

2011: 914

Census 2011 : India versus Bikaner Rajasthan

- The current sex ratio for total population in Rajasthan is 926 (Bikaner $=903$ ) per thousand male which is much less than the national average 940 .

- Sex ratio for 0-6 year age group population in Rajasthan is 883 while the national average is 914 .

This rate of decline is alarming. If this trend continues, there would be further reduction in the number of girls and women in future leading to serious socio-cultural problems including population imbalance and violence. Sex selective abortion is found to be a major factor responsible for this. The MTP Act was implemented in 1972 and the prenatal diagnostic techniques arrived in India in 1975 for determination of genetic abnormalities. However these techniques are widely used for determining the sex of the fetus and subsequent abortions if the fetus is female. To prevent this practice of sex selective

*Corresponding author: Mahendra Khatri, Resident, Department of Community Medicine, S.P. Medical College, Bikaner, Rajasthan, India, E-mail: dr_mahen79@yahoo.com

Received March 26, 2012; Published June 22, 2012

Citation: Khatri M, Acharya R, Sharma G (2012) Knowledge, Attitude and Practices (KAP) Related to Pre-Conception \& Pre-Natal Diagnostic Techniques (PC \& PNDT) Act Among the Antenatal Women in Bikaner. 1: 121. doi:10.4172/ scientificreports. 121

Copyright: (C) 2012 Khatri M, et al. This is an open-access article distributed under the terms of the Creative Commons Attribution License, which permits unrestricted use, distribution, and reproduction in any medium, provided the original author and source are credited. 
Citation: Khatri M, Acharya R, Sharma G (2012) Knowledge, Attitude and Practices (KAP) Related to Pre-Conception \& Pre-Natal Diagnostic Techniques (PC \& PNDT) Act Among the Antenatal Women in Bikaner. 1: 121. doi:10.4172/scientificreports.121

abortion using the prenatal diagnostic techniques, Government of India enacted the PNDT (Regulation and Prevention of Misuse) Act on 20.9. 1994. Subsequently this Act has been amended in 2002 and 2003 to Pre-conception and Pre-natal Diagnostic Techniques (PC \& PNDT), Prohibition of Sex Selection Rules. Although government is trying its best to increase the awareness of the people regarding the PC \& PNDT Act, it has not been reflected in practice yet. In contrast to the general trend in India, Pondicherry has shown an improvement in the sex ratio from $964 / 1000$ in 1991 to $990 / 1000$ in 2001 . The factors responsible for this positive change deserve to be studied and elucidated which can then be followed or taken care by other states with the negative trend.

Most of the female feticide cases in India are preventable and the PC \& PNDT Act is very helpful for reducing the rate of Female Feticide. Hence the emphasis of my study is to assess the knowledge, attitude \& practice related to PC \& PNDT Act among the pregnant women in Bikaner so that we can find out the various reasons of very less sex ratio in Bikaner and also to inform and educate them about PC \& PNDT Act so that this social evil of gender imbalance can be removed from the society by preventing the female feticide because it is very necessary for the overall socioeconomic progress of India.

\section{Materials and Methods}

During the study period over 6437 pregnant women visited for ANC in Antenatal OPD in Gynaecology \& Obstetrics department of Zanana Hospital associated with PBM group of hospitals and attached to S.P. Medical College, Bikaner and out of these 1000 antenatal women were selected for study. A systematic sample was taken (sampling interval: average number of adult women attending the clinic divided by 5). Only women of reproductive age (between 18 years up to 49 years) were selected for an interview. When a woman did not match the age criteria or refused for the interview, the next woman attending the consultation was selected. The reason of refusal was noted on a separate sheet.

\section{Study Period}

The study was proposed, planned and carried out between September 2011 to Febuary 2012.

\section{Type of study}

It is a Cross sectional study.

\section{Methodology}

- The Schedule contains form A, B and C.

- Form A includes family compositions, demographic and socioeconomic profile.

- Form B was framed in 3 separate sections for assessing Knowledge, Attitude \& Practice regarding PC \& PNDT Act in English thereafter the questions were asked individually person to person in Hindi/ local language of Bikaner and filled by myself. The study involved collection of information regarding knowledge and attitude of the Antenatal Women about PC \& PNDT ACT using multiple choice questions (MCQs). The variables included to evaluate knowledge on PC \& PNDT ACT were, awareness about declining sex ratio, possibility of intra uterine sex determination and methods, punishment associated with misuse of PC \& PNDT ACT and its extent. The attitude of Antenatal Women was assessed by questions like whether they will like to determine the sex of the fetus, if sex of the fetus is opposite what they will like to do and if their friend
/ family members wants to do in-utero sex determination what they will advise.

- A separate form C was also framed for assessment of Practices about PC \& PNDT Act .In this form the variables included to evaluate practices were miscarriage rate, MTP, sex determination and sex selective abortion etc.

- After explaining the purpose of the study the consent was taken from Antenatal Women. The Antenatal Women were also being informed the purpose of the study and to ensure that it would not affect the consequences of her delivery .After that the questions were asked.

- The KAP schedule was scored in order to create an index score upon which to evaluate participants' knowledge, attitudes and practices. Each question was graded as highly important, moderately important, or important. Each "highly important" question was given 5 points for the correct answer(s); 3 points for moderately important; and 1 point for important. Thus for a correct answer to a highly important question, respondents score 5 points and 0 for a wrong answer. Those who score $60 \%$ or more were included as having knowledge or having positive attitude. This allows a weighted index score to be given to each schedule. The weighted index scores of respondents will then give an accurate measure of the level of knowledge, attitude, and practices in terms PC \& PNDT Act. The scores were used to describe levels of knowledge attitudes and practice in relation to dependent variables (e.g. age, socio-economic status, literacy, parity, caste, religion etc).

The data were collected and then analyzed by SPSS Software.

\section{Result}

Statistically highly significant relationship between the literacy status and knowledge regarding PC \& PNDT Act was found (Table-1).The present study also shows that there is a relationship between knowledge regarding PC \& PNDT Act with Socioeconomic status and Parity which is highly significant. (Table 2 \& Table 3) It is found that there is highly significant relationship between the literacy status, Parity \& age with preference of male child. (Table $4 \&$ Table 5) The study population also showed that $64.9 \%$ women have positive attitude towards the PC \& PNDT Act while only $35.1 \%$ have negative attitude. It is found that association between attitude and age, Literacy, socioeconomic status \& parity was highly significant while association between attitude and religion was not significant. (Table 6 to Table 9) During assessment of practices it is found that $98.8 \%$ of study population is willing to increase the awareness of PC \& PNDT Act and $98 \%$ women are agreeing to provide the equal opportunity for son and daughter. $88.9 \%$ women confessed that they have right

\begin{tabular}{|l|l|c|c|c|}
\hline \multirow{2}{*}{ S.NO. } & \multirow{2}{*}{$\begin{array}{l}\text { LITERACY } \\
\text { STATUS }\end{array}$} & \multicolumn{2}{|c|}{$\begin{array}{r}\text { KNOWLEDEGE ABOUT } \\
\text { PC\& PNDT ACT }\end{array}$} & \multirow{2}{*}{ TOTAL } \\
\cline { 3 - 4 } & & YES & NO & \\
\hline 1 & ILLITERATE & $191(41.9 \%)$ & $264(58.1 \%)$ & $455(100 \%)$ \\
\hline 2 & PRIMARY\& MIDDLE & $150(50.3 \%)$ & $148(49.7 \%)$ & $298(100 \%)$ \\
\hline 3 & $\begin{array}{l}\text { SECONDARY } \\
\text { HIGHER SECONDARY }\end{array}$ & $138(70.7 \%)$ & $57(29.3 \%)$ & $195(100 \%)$ \\
\hline 4 & GRADUATE \& ABOVE & $45(86.5 \%)$ & $7(13.5 \%)$ & $52(100 \%)$ \\
\hline & TOTAL & $524(52.4 \%)$ & $476(47.6 \%)$ & $1000(100 \%)$ \\
\hline
\end{tabular}

*The $\mathrm{X} 2$ statistic for the data above is 66.89 with 3 Degrees of freedom, $\mathrm{P}<0.001$

Table 1: association of knowledge about pc \& PNDT act with literacy status of antenatal women. 
Citation: Khatri M, Acharya R, Sharma G (2012) Knowledge, Attitude and Practices (KAP) Related to Pre-Conception \& Pre-Natal Diagnostic Techniques (PC \& PNDT) Act Among the Antenatal Women in Bikaner. 1: 121. doi:10.4172/scientificreports.121

\begin{tabular}{|l|l|l|l|l|}
\hline S.NO. & $\begin{array}{l}\text { SOCIO ECONOMIC } \\
\text { STATUS }\end{array}$ & $\begin{array}{l}\text { KNOWLEDEGE ABOUT PC\& PNDT } \\
\text { ACT }\end{array}$ & TOTAL \\
\cline { 3 - 4 } & YES & NO & \\
\hline 1 & I & $90(66.1 \%)$ & $46(35.9 \%)$ & $136(100 \%)$ \\
\hline 2 & II & $154(56.2 \%)$ & $120(43.8 \%)$ & $274(100 \%)$ \\
\hline 3 & III & $181(50.2 \%)$ & $179(49.8 \%)$ & $360(100 \%)$ \\
\hline 4 & IV & $92(43.6 \%)$ & $119(56.4 \%)$ & $211(100 \%)$ \\
\hline 5 & V & $7(36.8 \%)$ & $12(63.2 \%)$ & $19(100 \%)$ \\
\hline & TOTAL & $524(52.4 \%)$ & $476(47.6 \%)$ & $\begin{array}{l}1000 \\
(100 \%)\end{array}$ \\
\hline
\end{tabular}

${ }^{*} \mathrm{X} 2$ statistic for the data above is 20.95 with 4 Degrees of freedom, $\mathrm{P}<0.001$

Table 2: association of knowledge about pc \& PNDT act with socioeconomic status of antenatal women.

\begin{tabular}{|l|l|l|l|l|}
\hline \multirow{2}{*}{ S.NO. } & \multirow{3}{|c|}{ CASTE } & $\begin{array}{l}\text { KNOWLEDEGE ABOUT PC\& } \\
\text { PNDT ACT }\end{array}$ & TOTAL \\
\cline { 3 - 5 } & & YES & NO & \\
\hline 1 & PRIMIPARA & $151(42.06 \%)$ & $208(57.94 \%)$ & $359(100 \%)$ \\
\hline 2 & MULTIPARA & $354(57.9 \%)$ & $257(42.1 \%)$ & $611(100 \%)$ \\
\hline 3 & GRAND MULTIPARA & $19(63.3 \%)$ & $11(36.7 \%)$ & $30(100 \%)$ \\
\hline & TOTAL & $524(52.4 \%)$ & $476(47.6 \%)$ & $1000(100 \%)$ \\
\hline
\end{tabular}

*The $\mathrm{X} 2$ statistic for the data above is 24.36 with 2 Degrees of freedom, $\mathrm{P}<0.001$

Table 3: association of knowledge about pc \& PNDT act with parity of antenatal women.

\begin{tabular}{|l|l|l|l|l|}
\hline \multirow{2}{*}{ S.NO. } & \multirow{2}{|l|}{$\begin{array}{l}\text { LITERACY } \\
\text { STATUS }\end{array}$} & \multicolumn{2}{l|}{$\begin{array}{l}\text { PREFERENCE OF MALE } \\
\text { CHILD }\end{array}$} & \multirow{2}{*}{ TOTAL } \\
\cline { 2 - 4 } & YES & NO & \\
\hline 1 & ILLITERATE & $373(81.9 \%)$ & $82(19.1 \%)$ & $455(100 \%)$ \\
\hline 2 & PRIMARY\& MIDDLE & $179(60.06 \%)$ & $119(39.94 \%)$ & $298(100 \%)$ \\
\hline 3 & $\begin{array}{l}\text { SECONDARY \& HIGHER } \\
\text { SECONDARY }\end{array}$ & $107(54.8 \%)$ & $88(45.2 \%)$ & $195(100 \%)$ \\
\hline 4 & GRADUATE \& ABOVE & $19(36.5 \%)$ & $33(63.5 \%)$ & $52(100 \%)$ \\
\hline & TOTAL & $678(67.8 \%)$ & $322(32.2 \%)$ & $1000(100 \%)$ \\
\hline
\end{tabular}

*The $\mathrm{X} 2$ statistic for the data above is 88.12 with 3 Degrees of freedom, $\mathrm{P}<0.001$

Table 4: association between literacy status and preference for male child.

\begin{tabular}{|c|c|c|c|c|}
\hline \multirow{2}{*}{ S.NO. } & \multirow{2}{*}{ BIRTH ORDER } & \multicolumn{2}{|c|}{ PREFERENCE OF MALE } & \multirow{2}{*}{ TOTAL } \\
\cline { 3 - 4 } & & YES & NO & \\
\hline 1 & PRIMIPARA & $211(58.7 \%)$ & $148(41.3 \%)$ & $359(100 \%)$ \\
\hline 2 & MULTIPARA & $441(72.1 \%)$ & $170(17.9 \%)$ & $611(100 \%)$ \\
\hline 3 & $\begin{array}{c}\text { GRAND } \\
\text { MULTIPARA }\end{array}$ & $26(86.6 \%)$ & $4(13.4 \%)$ & $30(100 \%)$ \\
\hline & TOTAL & $678(67.8 \%)$ & $322(32.2 \%)$ & $1000(100 \%)$ \\
\hline
\end{tabular}

*The $\mathrm{X} 2$ statistic for the data above is 23.72 with 2 Degrees of freedom, $\mathrm{P}<0.001$

Table 5: association between parity and preference for male child.

to take their own decisions for the fate of you fetus. $84.6 \%$ want to prevent the female feticide.16\% study population confessed that will go for sex determination before delivery in future. (Table-10) $12.9 \%$ of study population confessed that they have done MTP during previous pregnancy. Majority of them done due to already having two or more daughters $(43.41 \%)$ and $18.61 \%$ having already a daughter while $21.71 \%$ have done MTP due to Family/ Husband's pressure. (Table 11)11.4\% of study population has confessed that they will go for MTP in future. Out of them majority (62.28\%) will do due to preference of male child and $16.67 \%$ will do due to already having daughter/daughters. (Table 12).

There is increasing trends of knowledge about PC \& PNDT Act is seen with increase of literacy status. The difference of knowledge about PC \& PNDT Act with Literacy status varies between 41.9\% among illiterate to $86.5 \%$ among Graduate \& above. These observations are found statistically highly significant.

There is increasing trends of knowledge about PC \& PNDT Act is seen with higher socioeconomic group. The difference of knowledge about PC \& PNDT Act varies between 36.5\% among class $\mathrm{V}$ to $66.1 \%$ among class I .These observations are statistically highly significant. The difference of knowledge about PC \& PNDT Act with Parity varied between $42.06 \%$ in Primipara to $63.3 \%$ in Grand Multipara. These observations are found statistically highly significant. There is increasing trends of preference for male child is seen with decreasing literacy status. The difference of preference for male child varies between $36.5 \%$ among graduate \& above to $81.9 \%$ among illiterate. These observations are statistically highly significant. There is increasing trends of preference for male child is seen as the parity status is increased from Primipara to Grand Multipara. The difference of preference for male child varies between 58.7\% among Primipara to $86.6 \%$ among Grand Multipara women. These observations are statistically highly significant.

*(No women between age 43 to 49 yrs. visited antenatal clinic during the study period for antenatal check up)

An increasing trends of Positive Attitude about PC \& PNDT Act is seen with increasing age. The Positive Attitude about PC \& PNDT

\begin{tabular}{|l|c|c|c|}
\hline \multirow{2}{*}{ AGE (Yrs.) } & \multicolumn{2}{|c|}{ ATTITUDE } & \multirow{2}{*}{ TOTAL } \\
\cline { 2 - 3 } & POSITIVE & NEGETIVE & \\
\hline $18-22$ & $90(52.9 \%)$ & $80(47.1 \%)$ & $170(100 \%)$ \\
\hline $23-27$ & $238(62.1 \%)$ & $145(37.9 \%)$ & $383(100 \%)$ \\
\hline $28-32$ & $214(68.5 \%)$ & $98(31.5 \%)$ & $312(100 \%)$ \\
\hline $33-37$ & $74(76.2 \%)$ & $23(33.8 \%)$ & $97(100 \%)$ \\
\hline $38-42$ & $33(86.8 \%)$ & $5(13.2 \%)$ & $38(100 \%)$ \\
\hline TOTAL & $649(64.9 \%)$ & $351(35.1 \%)$ & $1000(100 \%)$ \\
\hline
\end{tabular}

*The $\mathrm{X} 2$ statistic for the data above is 27.50 with 4 Degrees of freedom, $\mathrm{P}<0.001$

Table 6: association of attitude regarding pc \& PNDT act with age of antenatal women.

\begin{tabular}{|l|c|c|c|}
\hline \multirow{2}{*}{ LITERACY STATUS } & \multicolumn{2}{|c|}{ ATTITUDE } & \multirow{2}{*}{ TOTAL } \\
\cline { 2 - 3 } & POSITIVE & NEGETIVE & \\
\hline ILLITERATE & $260(57.1 \%)$ & $195(42.9 \%)$ & $455(100 \%)$ \\
\hline $\begin{array}{l}\text { PRIMARY\& } \\
\text { MIDDLE }\end{array}$ & $206(69.1 \%)$ & $92(30.9 \%)$ & $298(100 \%)$ \\
\hline $\begin{array}{l}\text { SECONDARY \& HIGHER } \\
\text { SECONDARY }\end{array}$ & $139(71.2 \%)$ & $56(28.8 \%)$ & $195(100 \%)$ \\
\hline GRADUATE \& ABOVE & $44(84.6 \%)$ & $8(15.4 \%)$ & $52(100 \%)$ \\
\hline TOTAL & $649(64.9 \%)$ & $351(35.1 \%)$ & $1000(100 \%)$ \\
\hline
\end{tabular}

${ }^{*}$ The $\mathrm{X} 2$ statistic for the data above is 26.75 with 3 Degrees of freedom, $\mathrm{P}<0.001$

Table 7: association of attitude regarding pc \& PNDT act with literacy status of antenatal women.

\begin{tabular}{|l|c|c|c|}
\hline \multirow{2}{*}{$\begin{array}{l}\text { SOCIOECONOMIC } \\
\text { STATUS }\end{array}$} & \multicolumn{2}{|c|}{ ATTITUDE } & \multirow{2}{*}{ TOTAL } \\
\cline { 2 - 3 } & POSITIVE & NEGETIVE & \\
\hline I & $70(51.4 \%)$ & $66(48.6 \%)$ & $136(100 \%)$ \\
\hline II & $165(60.2 \%)$ & $109(39.8 \%)$ & $274(100 \%)$ \\
\hline IV & $238(66.1 \%)$ & $122(33.9 \%)$ & $360(100 \%)$ \\
\hline V & $162(77.1 \%)$ & $48(22.9 \%)$ & $210(100 \%)$ \\
\hline TOTAL & $14(70 \%)$ & $6(30 \%)$ & $20(100 \%)$ \\
\hline
\end{tabular}

*The $\mathrm{X} 2$ statistic for the data above is 27.68 with 4 Degrees of freedom, $\mathrm{P}<0.001$

Table 8: association of attitude regarding pc \& PNDT act with socioeconomic status of antenatal women. 
Citation: Khatri M, Acharya R, Sharma G (2012) Knowledge, Attitude and Practices (KAP) Related to Pre-Conception \& Pre-Natal Diagnostic Techniques (PC \& PNDT) Act Among the Antenatal Women in Bikaner. 1: 121. doi:10.4172/scientificreports.121

Page 4 of 7

\begin{tabular}{|l|c|c|c|}
\hline \multirow{2}{*}{ PARITY } & \multicolumn{2}{|c|}{ ATTITUDE } & \multirow{2}{*}{ TOTAL } \\
\cline { 2 - 3 } & POSITIVE & NEGETIVE & \\
\hline PRIMI PARA & $270(75.2 \%)$ & $89(24.8 \%)$ & $359(100 \%)$ \\
\hline MULTI PARA & $366(59.9 \%)$ & $245(41.1 \%)$ & $611(100 \%)$ \\
\hline GRAND MULTI PARA & $13(43.3 \%)$ & $17(56.7 \%)$ & $30(100 \%)$ \\
\hline TOTAL & $649(64.9 \%)$ & $351(35.1 \%)$ & $1000(100 \%)$ \\
\hline
\end{tabular}

*The $\mathrm{X} 2$ statistic for the data above is 29.39 with 2 Degrees of freedom, $\mathrm{P}<0.001$

Table 9: association of attitude regarding pc \& PNDT act with parity of antenatal women.

\begin{tabular}{|l|l|c|c|c|}
\hline S.No. & PRACTICES & YES & NO & TOTAL \\
\hline 1. & Will contribute to prevent Female Feticide & 846 & 154 & 1000 \\
\hline 2. & Will go for sex determination before delivery & 160 & 840 & 1000 \\
\hline 3. & $\begin{array}{l}\text { Will go for a genetic counseling before } \\
\text { conception for the purpose of having a son }\end{array}$ & 23 & 977 & 1000 \\
\hline 4. & $\begin{array}{l}\text { Will use modern techniques of (PC\& PNDT) } \\
\text { in future }\end{array}$ & 201 & 799 & 1000 \\
\hline 5. & $\begin{array}{l}\text { Will provide equal opportunities for son and } \\
\text { daughter }\end{array}$ & 980 & 20 & 1000 \\
\hline 6. & $\begin{array}{l}\text { Have right to take your own decisions for the } \\
\text { fate of your fetus }\end{array}$ & 889 & 111 & 1000 \\
\hline 7. & $\begin{array}{l}\text { Will help for increasing the awareness about } \\
\text { the PC \& PNDT act in the community }\end{array}$ & 988 & 12 & 1000 \\
\hline
\end{tabular}

Table 10: assessment of practices about pc \& pndt act among study population.

\begin{tabular}{|c|l|c|}
\hline S.NO. & REASON & $\mathrm{n}=129$ \\
\hline 1. & Advised by doctor & $10(7.75 \%)$ \\
\hline 2. & Have already a daughter & $24(18.61 \%)$ \\
\hline 3. & Have already two or more than two daughters & $56(43.41 \%)$ \\
\hline 4. & Due to Family/ Husband's pressure & $28(21.71 \%)$ \\
\hline 5. & Contraception Failure & $11(8.52 \%)$ \\
\hline
\end{tabular}

Table 11: assessment of reasons for MTP.

\begin{tabular}{|c|l|c|}
\hline S.NO. & REASON & $\mathrm{n}=114$ \\
\hline 1. & For preference of Male Child & $71(62.28 \%)$ \\
\hline 2. & Already have Daughter / daughters & $19(16.67 \%)$ \\
\hline 3. & Pressure by Husband / In-laws & $10(8.77 \%)$ \\
\hline 4. & Cannot afford a female child due to poor economic status & $14(12.28 \%)$ \\
\hline
\end{tabular}

Table 12: assessment of reasons for use of MTP in future.

Act with Age varies between $52 \% .9$ to $86.8 \%$. The difference in attitude with age is highly significant. There is increasing trends of Positive Attitude about PC \& PNDT Act with increasing Literacy status. The Positive Attitude about PC \& PNDT Act increases with Literacy from $57.1 \%$ among Illiterate to $84.6 \%$ in Graduate \& above. This difference is statistically highly significant. Highly statistical significant difference of Positive Attitude about PC \& PNDT Act is seen with change in socioeconomic status, where as the positive attitude among the highest socioeconomic class is least (51.4\%), it is maximum amongst the lower socioeconomic class $(77.1 \%$ in class IV and $70 \%$ in class V). There is a decreasing trend of Positive Attitude with parity. The Positive Attitude about PC \& PNDT Act with parity decreases from 75.2\% (Primipara) to $43.3 \%$ (Grand Multipara). The difference in attitude with parity is statistically highly significant.98.8 \% of study population is willing to increase the awareness of PC \& PNDT Act and 98\% women are agreeing to provide the equal opportunity for son and daughter. $88.9 \%$ women answered that they have right to take their own decisions for the fate of their fetus. $84.6 \%$ want to prevent the female feticide. $16 \%$ study population confessed that will go for sex determination before delivery in future. Major reason given for undergoing MTP is already having daughter / daughters (62.02\%) other major reason for MTP is due to Family/ Husband's pressure (21.71\%).Majority (62.28\%) is willing for MTP due to preference of male child and $16.67 \%$ willing due to them already having daughter/daughters.

\section{Discussion}

During the study period over 6437 pregnant women visited for ANC in Antenatal OPD and out of these 1000 antenatal women were interviewed who were between the age group of 18-49 years and gave the consent for interview.

The overall knowledge about PC \& PNDT act among antenatal women was $52.4 \%$ in the present study which is much higher as compared to Srivastava study done in 2001 which showed only 32 $\%$ have knowledge about PC \& PNDT Act. The reason for higher awareness in present study may be that the Srivastava study was done in 2001 and at that time the literacy status was much lesser as compared to 2011 and also there is a big role of electronic media for increasing awareness and knowledge in last decade (2001-2010). As an impact of strong advertisement by diagnostic centers even illiterate group are now quite aware of the facility.

In study by $\mathrm{S}$. Ghose et al. maximum knowledge regarding PC \& PNDT Act was seen in age group 20-25 yrs.The knowledge decreased both above and below this age group. In the present study increasing trend of knowledge with age was seen, the knowledge about PC \& PNDT act among the various age group increased from $49.4 \%$ to $60.5 \%$ in the lowest to highest age group but the difference was not statistically significant.

S. Ghose et al. revealed in a study that there was good knowledge (75\%) about the PNDT Act among the pregnant women. High literacy status of women in Pondicherry (74.13\% for females) may have played a role. Srivastava et al. showed that awareness regarding PNDT Act was significantly associated with the literacy status of females, $62 \%$ of those who studied up to secondary were aware of PNDT Act as compared to less than $26 \%$ were aware among the illiterate group. In the present study also an increasing trends of knowledge about PC \& PNDT Act was seen with increase of literacy status. The difference of knowledge about PC \& PNDT Act with Literacy status varies between $41.9 \%$ among illiterate to $86.5 \%$ among Graduate \& above. These observations were found statistically highly significant. Education in general improves the status of women in the society and gives them a wider outlook and understanding beyond the confines of their family.

The Present study also revealed that there was increasing trends of knowledge about PC \& PNDT Act is seen with higher socioeconomic group. The difference of knowledge about PC \& PNDT act with socioeconomic status varies between $36.5 \%$ among class $\mathrm{V}$ to $66.1 \%$ among class I .These observations are statistically highly Significant.

There was also highly significant difference in knowledge about PC \& PNDT act with Parity status.

B N Vadera et al. showed that $58.5 \%$ of women gave preference to male child. A study carried out by Puri et al. showed that $56 \%$ women in the slums of Chandigarh showed preference to male child while in the present study it is $67.8 \%$ of all study population who gave the preference to male child.

The various reasons for son preference mentioned by the women include that he is the support and provider in old age; brings in dowry instead of draining family resources; keeps the family name alive; performs the last rites; on investing in sons, say on education or business, the wealth remains in the family. The main perceived reason for not wanting daughters was dowry by all the respondents. 
Every year, as millions of women marry, they dream of starting a family, of having their homes filled with tiny cries and the happy laughter of gurgling babies. In India however, pregnancy is too often followed by the question of whether the unborn child is a girl or a boy.

"Chhore Pe Baje Thali, Chhori Pe Thekere Phoren" is an old sentiment in the Indian state of Haryana which means "announce the birth of a son by beating of brass plates but at the birth of a daughter break earthen pots." Marriage in the Hindu fold of life is still traditionally considered essential for procreation and the continuation of the 'vansh' (lineage). Blessings showered on the bride during a wedding, consist of the line "Ashta Putra Sowbhagyavati Bhave" meaning "May you be blessed with eight sons." Thereafter on conception, mantras from the Atharva Veda, one of four most sacred books of Hinduism, are prescribed for chanting so that if the fetus is female it will be transformed into a male. The traditional joint family is patriarchal. Even though migration and increasing urbanization has led to more nuclear families, the patriarchal ways are still embedded in the psyche of the Indian man. Despite the legal emancipation of women in India, their education and employment in modern occupations, the traditional bias regarding female children has not undergone a change.

In most parts of the country son is a major obsession. One son is a cause for joy while two are seen as a lifetime for celebration, the traditional thinking being that if one dies, at least the other will live to take care of the parents. In the bargain, pressures on the woman to produce a son are unending. The girl child is seen as an economic drain as her marriage and dowry crushes her family under huge burden of debts.

Regarding preference of male child in the present study there was no significant difference was found among the various age groups, while increasing trends of Preference for male child was seen with decreasing literacy status. The difference of preference for male child varies between $36.5 \%$ among graduate \& above to $81.9 \%$ among illiterate. These observations are found statistically highly significant.

When comparison was done for male preference with various parity status, there was highly significant difference was found. The factors essentially responsible for contributing towards the declining sex ratio were son preference and dowry. The interesting finding is that the mushrooming of ultrasound clinics and the ability to pay for abortions was expressed by all the respondents as the major factors responsible for contributing to declining sex ratio.

The important reasons for son preference are social responsibilities taken by males, propagation of family name, support in the old age, to perform cremation and dowry. As per a report published by UNFPA in conjunction with Ministry of H\&FW and Office of Registrar General and Census Commissioner India 2003, there is a strong preference to son in India, which is influenced by many socio-economic and cultural factors, such as son being responsible to carry forward family name and occupation, Husband's or family pressure, source of support at the old age and to perform religious rites during cremation and practice of dowry. Dowry is a major reason for parents to resent a daughter birth and moreover they think it is pointless to spend so much on a girl education and upbringing only to leave for another's home, without repaying.

Regarding Attitude towards the PC \& PNDT Act $\mathbf{S}$ Ghose et al. revealed that a greater proportion (74.3\%) of the multipara, who is older in age had the Positive attitude as compared to the primipara (67.2\%) which though not significant was an important observation. Similarly in present study an increasing trends of Positive Attitude was seen with increase in parity. The difference of Positive Attitude about PC \& PNDT Act with Parity and age was statistically highly significant.

Multipara with lesser knowledge and urgency to complete the family must be under pressure from the family members to have a child with the desired sex, so is expected to favour sex determination. But their right attitude shows that inspite of lower knowledge and family pressure, women themselves do not want to waste their pregnancies and when faced with a situation where their pregnancy might get aborted, they do not favour sex selection. Analyzing education and attitude in our study group showed that up to graduation level, increase in education is accompanied with an improvement in the attitude in these ante-natal women. So, feel unnecessary to know the sex of the child prenatally. In India, the social milieu is such that a female child is the cause of much physical and mental torment to the mother irrespective of the background of the family.

Analyzing education and attitude in S. Ghose et al. study showed that up to graduation level, increase in education is accompanied with an improvement in the attitude in these ante-natal women. In my study it is revealed that there is increasing trends of Positive Attitude about PC \& PNDT Act is seen with increasing Literacy status. The difference of Positive Attitude about PC \& PNDT Act with Literacy varies between $57.1 \%$ to $84.6 \%$. These observations are statistically highly significant.

The reason for more positive Attitude among the more literate women may be that educated women are more in the favour of women empowerment and gender equality .So they feel that both male and female should have equal rights to live in the society.

Sneh Lata Tandon et al. revealed in a study that most of the women reported that they had gone for female feticide (MTP) under pressure from their husbands. Many a time the husbands would beat up their wives and force them for female feticide because in their view a female is an economic burden. In contrast in the present study the Positive Attitude was seen more amongst the subjects from lower socioeconomic group. Positive Attitude towards PC \& PNDT act varied between 51.4\% among social class I to $70 \%$ among social class V. This difference in attitude with socioeconomic class was statistically highly significant.

Now a days the higher social classes who are also more educated are more vulnerable for misuse of PC \& PNDT Act, sex determination, female feticide and preference of male child because they are approaching to more \& more advanced labs and ultrasonography centers .And once they came to know about the sex of fetus they either illegally abort the female fetus in India or go abroad for the abortion.

S. Ghose et al. found that nearly all of the respondents (98.9\%) profess that boys and girls should be given equal rights which almost similar in the present study which is $98 \%$. An integrated approach of Govt. and NGO's is desired. Govt. of India has done substantial work throwing considerable light on subjects of girl child through implementation of various programmes to restore the rights and dignities of girl child, giving her a world where she can live and dream and enrich our lives.

B N Vadera et al. shown in the study that $20.51 \%$ admitted that they will go for female feticide while in my study $11.4 \%$ women confessed that they will go for female feticide either due to family pressure or because they already had female child. It is also revealed that total 12.9 $\%$ of study population have gone through the MTP due to various reasons and from these women $8 \%$ have it done for sex preference as they already have one or more daughters while $2.8 \%$ women done it under family / husband's pressure. 
Citation: Khatri M, Acharya R, Sharma G (2012) Knowledge, Attitude and Practices (KAP) Related to Pre-Conception \& Pre-Natal Diagnostic Techniques (PC \& PNDT) Act Among the Antenatal Women in Bikaner. 1: 121. doi:10.4172/scientificreports.121

Page 6 of 7

In the Present study $21 \%$ of study population has experienced miscarriage in previous pregnancy. Out of them majority $(61.43 \%)$ have done MTP due to various reasons. $12.9 \%$ of study population has done MTP during previous pregnancy. Majority (43.41\%) of them done due to already having two or more daughters and $18.61 \%$ having already a daughter while $21.71 \%$ have done due to family/husband's pressure.

Study by AJ Singh et al. revealed that majority (67\%) of respondents had some test done during current pregnancy either for confirmation of pregnancy or they were advised by doctor to undergo the test. $13 \%$ women admitted that they had Sex Determination Test (SDT) done while in the present study it is found that $93.8 \%$ of study population reported that they had some test done during their current pregnancy. $65.8 \%$ had ultrasound test done for fetal well being as advised by the doctor, $13.3 \%$ women confessed that they did it for sex-determination.

The reason for increasing trend of use of prenatal diagnostic tests these days may be due to increase in awareness since last few years in the general population either due to increase in education or due to mass media like television, newspapers and internet. These days ulrasonography is advised to almost all pregnant women doctors for fetal well being or excluding any pathology.

Thakkar Dhwanee et al. showed in a study that $25.9 \%$ respondents reporting of ever been pressurized by their family members to undergo prenatal sex diagnosis of their fetus. In the present study $9.5 \%$ women confess that they have done the sex determination under the family / husband's pressure.

The Present study shows a clear picture of recent scenario of the female feticide and a strong desire for male child among the illiterate and multipara women already having the female child who are pressurized by family or husband and they are enforced to do the sex determination This calls for a need to educate women from under privileged population about gender equality and recommendations under PC \& PNDT act in order to improve declining sex ratio in our country. It was also found that women with higher socioeconomic status were having greater percentage of negative attitude.

\section{Conclusion}

After a detailed study and comparison of my work with other workers, it can be concluded that the present study shows a clear picture of factors affecting the knowledge and attitude towards the PC \& PNDT Act. The existence of son preference at an alarmingly high rate in our society is the root cause of imbalanced sex ratio. Moreover, the inclination to female feticide is reported by the subjects in spite of them being aware of the consequences of imbalance in sex ratio. Socio-demographic factors like age, literacy, socioeconomic status, parity sex of the previous child and pressure by family or husband affect the knowledge, attitude and practices towards the PC \& PNDT Act and woman's preference for her next child. These days higher social classes are more vulnerable for misuse of PC \& PNDT Act, doing sex selection, female feticide and preference of male child because they are approaching to more \& more advanced sex determination laboratories and USG centers. And once they came to know about the sex of fetus either illegally abort the female fetus in India or even go abroad for the abortion.

\section{Recommendations}

1. Awareness \& sensitization

2. Effective Monitoring and Implementation of Act
3. Elimination of negative cultural attitudes and practices against the girl

4. Elimination of all forms of discrimination against the girl child

5. Elimination of discrimination against the girl child in education, skills development and training

6. Elimination of discrimination against the girl child in health and nutrition

7. Elimination of girl child labor

8. Eradicate violence against the girl child

9. Promote the girl child's awareness of and participation in social, economic and political life

10. AND, FINALLY. A few pilot projects may be taken up in different parts of the country, more particularly in those States where the level of gender discrimination is more acute. It is important to initiate such projects, because however much we may bewail the failure of the constitutional and legislative support systems to provide protection to the girl child the harsh reality is that unless change occurs in society's own centuries old gender-discriminatory cultural attitudes and biases no governmental action can succeed by itself. It will be possible through the means of such projects to experiment with and test in live field conditions different approaches, in full collaboration with the community and families a large, so as to derive from the experience thereof actionable lessons on the most practical and efficacious means to alleviate these vexatious problems. There are numerous issues that call for new paradigms of action or strategic paradigm shifts. To mention a few-How can the role of the family be reoriented and strengthened in improving the status of the girl child? How could public awareness of the value of the girl child be increased and her status, self-image and self esteem strengthened? How could additional income generating opportunities and better livelihood options be made accessible to women in the family? How could opinion be built against such gruesome and unethical practices of prenatal sex selection, feticide and infanticide? How should families be made more conscious of the importance of better health care, nutrition and education for the girl child? These are the kind of issues that the pilot projects will be dealing with. Actionable approaches can be concretized through such experimental pilot projects. These field-tested measures and policy instruments could then be replicated on a larger scale. The pilot projects should be handed over for implementation to credible NGOs who have had experience of working on issues of this nature. The projects should be of five years duration, followed by an independent evaluation of the methodologies adopted, techniques developed and lessons learnt.

Removal of GD cannot be achieved by the health department alone, therefore, each one from the society such as parents, teachers, social scientists, doctors, lawyers, journalists, political and religious leaders within their own domain have to play a role to curb this practice.

\section{References}

1. Nanda AR. Addressing the reproductive health needs of adolescents in India: Directions for programs. Ministry of Health and Family Welfare, Government of India.

2. Walia A (2005) A Female foeticide in Punjab: Exploring the socioeconomic and cultural dimensions. IDEA 10:1

3. Khanna SK (1995) Prenatal sex determination - a new family building strategy Manushi 86: 23-29.

4. Singh AJ, Arora AK. Spontaneous and induced abortion in rural north India.

5. Mutharayappa R, Arnold F, Roy T.K (1996) Son preference and its impact on fertility in India, National family health subject reports no.3, Mumbai: International Institute for population sciences 4: 1-4.

6. Das N (1987) Sex preference and fertility behavior: A study of recent Indian data. Demography24:517.

7. S Puri, V Bhatia, HM Swami (2007) Gender Preference and Awareness Regarding Sex Determination among Married Women in Slums of Chandigarh. Indian Journal of Community Medicine 32: 60-62.

8. BN Vadera, UK Joshi, SV Unadakat, BS Yadav, Sudha Yadav(2007) Study on Knowledge, Attitude and Practices Regarding Gender Preference and Female Feticide Among Pregnant Women. Indian Journal of Community Medicine 32:300-301.

9. Malhi $\mathrm{P}$, Jagat $\mathrm{J}$ (1997) Is Son Preference Constraining Contraceptive Use in India? Guru Nanak Journal of Sociology 18:72-92. 
Citation: Khatri M, Acharya R, Sharma G (2012) Knowledge, Attitude and Practices (KAP) Related to Pre-Conception \& Pre-Natal Diagnostic Techniques (PC \& PNDT) Act Among the Antenatal Women in Bikaner. 1: 121. doi:10.4172/scientificreports.121

Page 7 of 7

10. Mutharayappa R, Choe, MK, Arnold F, Roy TK (1997) Son Preference and Its Effect on Fertility in India. National Family Health Survey.

11. S Monica Das Gupta (1987) Elective Discrimination against Female Children in Rural Punjab, India. Population and Development Review 13: 77-100.
12. Miller Barbara D (1981) The endangered sex: The neglect of female children in rural North India. Ithaca: Cornell University Press.

13. Bardhan PK (1988) Sex disparity in child survival in rural India : 473-480.

14. T. N. Srinivasan and P.K. Bardhaneds. Rural poverty in South India. 